\title{
PROCESSO DE FORMULAÇÃO ESTRATÉGICA EM UMA REDE DE FRANQUIAS DO SETOR FARMACÊUTICO
}

\section{RESUMO}

Compreender como o estrategista formula a estratégia organizacional é parte fundamental para entender melhor como as organizações alcançam e mantém suas vantagens competitivas. O objetivo deste estudo é identificar como ocorre o processo de formulação da estratégia pela perspectiva do indivíduo em uma rede de franquias do setor farmacêutico. Para tanto, considerou-se as três dimensões do processo de formulação estratégica de De Witt e Meyer que são: formulação, pensamento e mudança. Os resultados confirmam a existência de paradoxos no processo estratégico, e sugerem, para essa amostra, que os executivos formulam estratégias predominantemente criativas, emergentes e que há um equilíbrio entre mudanças evolucionárias e revolucionárias. Este artigo pode, por meio da identificação de como franqueador e franqueados formulam suas estratégias, auxiliar a determinação das estratégias adequadas no contexto das redes de franquias.

Palavras-chave: Formulação da estratégia; Franchising; Mapas cognitivos.

\begin{abstract}
Understand how the strategist formulates the organizational strategy is a key part to better understand how organizations achieve and maintain their competitive advantage. The aim of this study is to identify how the process of formulating the strategy from the individual's perspective is on a pharmaceutical industry franchises. Therefore, was considered the three dimensions of the strategy formulation process of De Witt and Meyer. The results confirm the existence of paradoxes in the strategic process, and suggest, for this sample, that executives formulate predominantly creative strategies, emerging and that there is a balance between evolutionary and revolutionary changes strategies. This article may, by identifying how franchisor and franchisees formulate their strategies, help to determining the appropriate strategies in the context of franchise networks.
\end{abstract}

Keywords: Strategy Formulation; Franchising; Cognitive Maps. 


\section{PROCESO DE FORMULACIÓN ESTRATÉGICA EN UNA RED DE FRANQUICIA FARMACÉUTICA}

\section{RESUMEN}

Comprender cómo se formula la estrategia de la organización es una parte clave para comprender mejor cómo las organizaciones logran y mantienen su ventaja competitiva. El objetivo de este estudio es identificar cómo ocurre el proceso de formulación de la estrategia desde la perspectiva del individuo en una red de franquicias de la industria farmacéutica. Por lo tanto, se consideró las tres dimensiones del proceso de formulación de la estrategia de De Witt y Meyer que son: formulación, pensamiento y mudanzas. Los resultados confirman la existencia de las paradojas en el proceso estratégico, y sugieren para esta muestra, que los ejecutivos formulan estrategias predominantemente creativas, emergentes y de que hay un equilibrio entre las estrategias de cambios evolutivos y revolucionarios. Este artículo puede, mediante la identificación de cómo franquiciador y franquiciados formulan sus estrategias adecuadas para ayudar en el contexto de las redes de franquicia.

Palabras clave: Estrategia de formulación; Franquía; Mapas cognitivos.

Guilherme Smaniotto Tres ${ }^{1}$ Marcel Lima Ribeiro Dantas ${ }^{2}$ Diego Philipe de Oliveira Godeiro ${ }^{3}$ Afrânio Galdino de Araújo ${ }^{4}$

\footnotetext{
${ }^{1}$ Mestre em Administração pela Universidade Nove de Julho - Uninove. Brasil. E-mail: guis3@ hotmail.com

${ }^{2}$ Mestre em Administração pela Universidade Potiguar - UnP. Professor da Universidade Potiguar - UnP. Brasil. E-mail: marcellrdantas@yahoo.com.br

${ }^{3}$ Mestre em Engenharia de Produção pela Universidade Federal do Rio Grande do Norte - UFRN. Brasil. Email: diegophilipe@ @otmail.com

${ }^{4}$ Doutor em Engenharia de Produção pela Universidade Federal de Pernambuco - UFPE. Professor da Universidade Federal do Rio Grande do Norte - UFRN. Brasil. E-mail: afranioga @ gmail.com
} 


\section{INTRODUÇÃO}

O processo de formular e implementar estratégias é um dos aspectos mais relevantes realizados pelos executivos para que as organizações estabeleçam e mantenham suas vantagens competitivas (Oliveira, 2014; Eisenhardt; Kahwajy \& Bourgeois, 1997). Pesquisadores, tais como Tripsas e Gavetti (2000), Reger e Huff (1993), Bogner e Thomas (1993), buscaram sondar a mente do estrategista para compreender, entre outros aspectos, a formulação da estratégia como um processo cognitivo.

O processo de formulação estratégica, sob a perspectiva de como as decisões são tomadas em âmbito individual, está ligado a como o estrategista pensa. Os resultados da tomada de decisão são difíceis de prever em sua plenitude (Kahneman \& Tversky, 1979), Lucian et al. (2008) argumentaram que o caminho a ser seguido pela organização não é fácil, uma vez que os executivos frequentemente tomam decisões que se configuram como processos complexos na mente do estrategista. Neste contexto, De Wit e Meyer (2004) propuseram um construto para avaliar a formulação da estratégia na perspectiva do indivíduo por meio das dimensões: pensamento estratégico, formação estratégica e mudança estratégica.

As empresas abordadas neste estudo foram farmácias de manipulação de uma das maiores redes de franquias do Brasil neste segmento. Farmácias de manipulação são, em sua maioria, micro ou pequenas empresas. É importante destacar que no Brasil há mais 5.500 farmácias deste tipo que geram mais de 60 mil empregos diretos e 240 mil empregos indiretos e juntas representam, aproximadamente, $10 \%$ de todo o mercado de medicamentos do país (Anfarmag apud Bonfilio et al., 2010). Outra característica marcante é a enorme competitividade no setor, o que força as farmácias a desenvolverem modelos de negócios que viabilizem a vantagem competitiva. Nesse sentido, a formação de franquias tem sido um dos tipos de aliança mais procurados pelo varejo farmacêutico (Ribeiro \& Prieto, 2009).

O sistema de franquias ganha proeminência e atrai interesse de pesquisadores que buscam compreender melhor suas implicações econômicas e estratégicas (Davidovitsch; Caldas \& Silva, 2009). Além do ambiente acadêmico, as franquias ganham relevância econômica. No período entre 2003 e 2014, o faturamento do sistema de franquias no Brasil passou de 29,044 para 127,331 bilhões de reais, o número de unidades franqueadas aumentou de 56.564 para 125.641, enquanto o número de redes, saltou de 678 para 2.942 (Associação Brasileira de Franchising, 2015). O sistema de franquia é composto por duas partes distintas, o franqueador, detentor da marca e o do conhecimento da gestão do negócio, e os franqueados, múltiplos agentes econômicos (Silva \&Azevedo, 2007). Trata-se de um sistema baseado na cooperação entre as partes (Dias, 2004; Rocha, 2010).

O processo de formulação da estratégia em empresas que usam o sistema de franquia ainda carece de estudos mais aprofundados (Ribeiro \& Pieto, 2009). Além disso, há várias pesquisas sobre estratégias empresariais em grandes empresas que apresentam conceitos e modelos que podem não ser perfeitamente aplicáveis em pequenas empresas (Rocha et al., 2011). Nesse contexto, surgem os seguintes questionamentos: como executivos de redes de franquias formulam suas estratégias? O pensamento desses executivos se inclina para o racional/lógico ou para o criativo? A formação de suas estratégias é predominantemente deliberada ou emergente? As mudanças são evolucionárias ou revolucionárias? Assim, este artigo busca aprofundamento na teoria sobre formulação estratégica a partir de um instrumento de pesquisa elaborado por Lucian et al. (2008) e aplicado em uma rede formada por micro e pequenas empresas do segmento de farmácias de manipulação que utiliza franchising como modelo de negócio.

Além desta introdução, o artigo está subdividido nos seguintes tópicos: referencial teórico, que é composto pelos constructos relativos ao processo de formulação estratégica sob a perspectiva do indivíduo, tendo como base os estudos de De Witt e Meyer (2004) e sobre franchising; método; resultados, discussão e considerações finais.

\section{REFERENCIAL TEÓRICO}

\section{Formulação estratégica}

A alta administração de uma empresa é responsável pelas tomadas de decisões que guiam a empresa para seus objetivos escolhidos (Eisenhardt et al. 1997; Hambrick \& Mason, 1984). Neste contexto, estabelecer e implementar estratégias empresariais é um dos aspectos mais relevantes realizados pelos executivos da alta administração, que é composto por cinco etapas essenciais citadas a seguir: (i) formulação das estratégias empresariais; (ii) estabelecimento das estratégias alternativas; (iii) escolha das estratégias empresariais alternativas; (iv) implementação das estratégias empresariais e (v) controle, avaliação e acompanhamento das estratégias empresariais (Oliveira, 2014). 
A maneira como as estratégias são formuladas e implementadas não é um processo idêntico em todas as organizações, resultando de uma combinação de fatores externos (características e condições do ambiente) e de condições internas (dimensão, capacidades materiais, humanas e organizacionais) que configuram cada situação particular. Assim, uma organização, em razão de seus valores, sua cultura, sua capacidade financeira e seus objetivos, deve encontrar o melhor modelo de formulação e implementação das estratégias que fornecerão a base para seu sucesso ou insucesso (Meirelles et al.,2000).

A formulação estratégica pode ser entendida como um processo mental (Mintezberg; Ahlstrand \& Lampel, 2010). Para tanto, é preciso sondar a mente do estrategista. Esse enfoque ganhou projeção por meio de pesquisadores como Tripsas e Gavetti (2000), Reger e Huff (1993), Bogner e
Thomas (1993). Posteriormente De Wit e Meyer (2004) propuseram um construto que trata a formulação da estratégia, por meio das dimensões pensamento estratégico, formação estratégica e mudança estratégica. Cada uma dessas dimensões é tratada por meio de um continuum com os seus paradoxos.

A primeira dimensão do paradoxo proposto por Wit e Meyer (2004) é a dimensão pensamento estratégico. Nesse paradoxo, há, de um lado, o pensamento lógico e no outro, o pensamento criativo. Já na dimensão formulação estratégica, em um extremo temos, de um lado, a formulação estratégica deliberada e, no outro, a formulação estratégica emergente. Por fim, temos o paradoxo entre a mudança estratégica revolucionária e a mudança estratégica evolucionária. A Figura 1 ilustra os três paradoxos da formulação da estratégia, segundo De Wit e Meyer (2004).

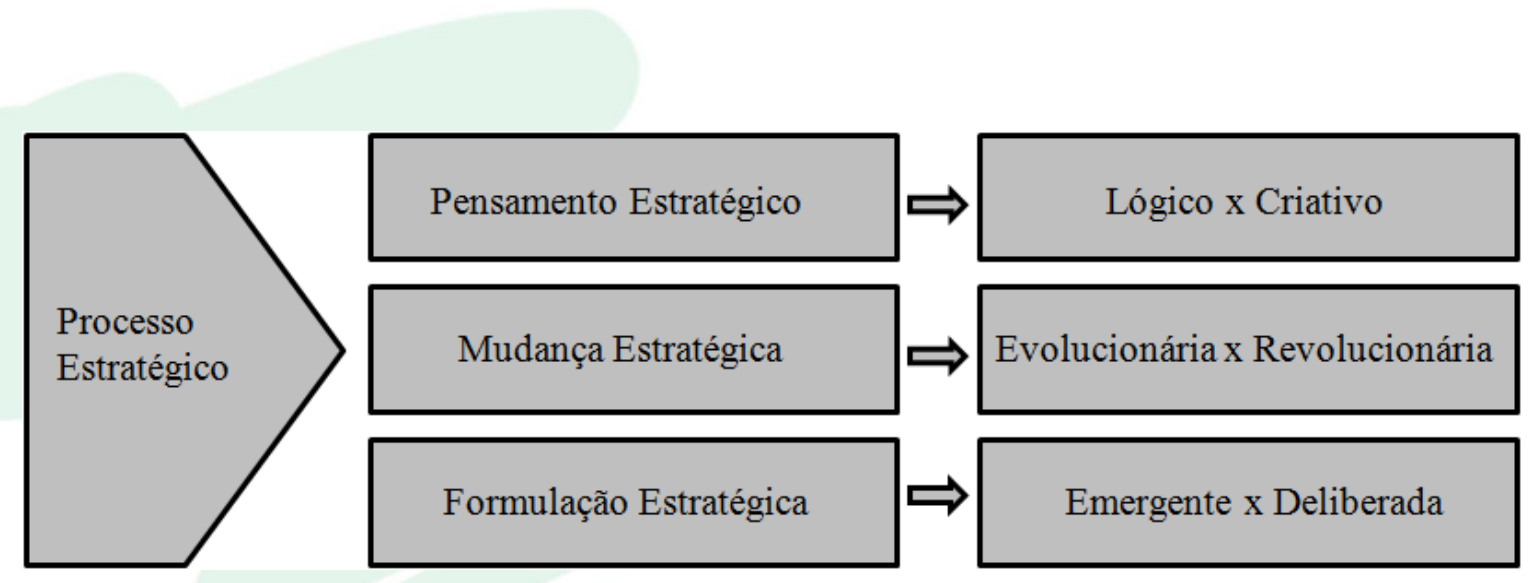

Figura 1 - Tensões do processo de formulação estratégica Fonte: Adaptado de De Wit e Meyer (2004)

O uso de processos ultrapassados ou influenciados por fatores emocionais são evitados pelo uso do pensamento lógico (Lucian \& Sousa Filho, 2009). Por outro lado, estrategistas que usam o pensamento criativo se utilizam, sobretudo, da intuição, uma vez que acreditam que os modelos de formulação estratégica são limitados e insuficientes (Moore, 2006).

Para Mintzberg, Ahlstrand e Lampel (2010), o conceito de estratégia está relacionado à construção de cenários e planos de ação que garantam um posicionamento da organização em relação a este cenário. Assim, estratégias deliberadas são aquelas planejadas pela organização para serem implantadas em um determinado contexto. Entretanto, nem sempre é possível adotar estratégias planejadas previamente, visto que o ambiente onde as organizações atuam é mutante.
Estratégia deliberada adotada por uma organização pode estar baseada em um planejamento que pode não fazer mais sentido em decorrência de uma grave crise econômica mundial, por exemplo. Na estratégia emergente, o ambiente possui importância máxima, já que o próprio desenvolvimento da organização é produto de sua relação com o meio e das constantes mudanças trazidas por ele. Segundo Mintzberg, Ahlstrand e Lampel (2010), as organizações não devem trabalhar apenas com estratégias deliberadas, pois pode haver demasiado apego ao cenário construído previamente, nem apenas com estratégias emergentes, situação na qual a organização será apenas reativa às condições ambientais, podendo causar a impressão que está perdida. As estratégias, assim, são um filtro entre o planejamento formal e as possibilidades de atuação no curto prazo. 
Qualquer empresa pode romper com o passado e mudar de forma revolucionária. Tushman \& O'Reilly (1996) apontam que qualquer empresa deve mudar de maneira revolucionária em busca de um nível superior de desempenho. Para autores, como Marrick (1998), a mudança revolucionária é o caminho para se alcançar a liderança de mercado. Já as mudanças evolucionárias ocorrem por meio de pequenas mudanças que acontecem durante toda a história da empresa e são norteadas pelo aprendizado organizacional (Lucian \& Sousa Filho, 2009).

\section{Formulação estratégica no franchising}

A obtenção de vantagem competitiva pode se dar de várias formas no sistema de franchising. De maneira geral, Porter (1986) assevera que a essência da formulação da estratégica consiste em alinhar uma empresa ao seu ambiente em busca de vantagem competitiva decorrente da diferenciação perante os concorrentes ou por meio da redução de custos. Em um outro ponto de vista, apontado por, para Barney (2002) e Wernerfelt (1984), a vantagem competitiva recai sobre os fatores internos, ou seja, pela utilização dos recursos, das competências e capacidades de uma empresa.

Thompson e Strickland III (2001), afirmaram que a vantagem competitiva pode ser alcançada por meio de alianças empresariais, o que se mostra como alternativa para alcançar recursos e habilidades que não seriam atingidos por uma empresa isolada. A relação entre franqueador e franqueado no sistema de franquias é de cooperação (Dias, 2004; Rocha, 2010). Essa característica é importante para o desenvolvimento do negócio.

Diversos autores discorrem sobre as vantagens e desvantagens do sistema do franchising para franqueador e franqueado. As principais vantagens apontadas para o franqueador são a rapidez de expansão da rede, menor custo de expansão, fortalecimento da marca, cobertura geográfica mais eficiente e estratégica, ausência de relação empregatícia, economia de escala (Gohr; Santos \& Maggioni, 2011; Merlo, 2000; Patrício, 2007; Rocha, 2010). Enquanto as principais desvantagens seriam a perda parcial do controle, maior custo de supervisão, rentabilidade diminuída, disputa entre franqueados, entre outros (Gohr; Santos \& Maggioni, 2011; Merlo, 2000; Patrício, 2007; Rocha, 2010). A utilização de sistema operacional desenvolvido, marca já conhecida, economias de escala, assistência técnica e apoio administrativo e risco diminuído em relação a negócio próprio podem ser vistas como as principais vantagens para o franqueado (Gohr; Santos \& Maggioni, 2011; Merlo, 2000; Patrício,
2007; Rocha, 2010). Como principais desvantagens para o franqueado, pontua-se a perda da autonomia na gestão, pouco espaço para iniciativas individuais, limitação de produtos/serviços a serem oferecidos e sistema pouco flexível que pode propiciar conflito com o franqueador (Gohr; Santos \& Maggioni, 2011; Merlo, 2000; Patrício, 2007; Rocha, 2010).

A desatualização de um produto ou de todo um know-how é danosa para um negócio e é possível que o seja ainda mais para uma rede de franchising por razões de mercado, bem como para manter os seus e atrair novos franqueados. Neste contexto, ao franqueador compete monitorar o ambiente externo da rede, conceber e desenvolver inovações, gerir a implantação de inovações e coordenar a colaboração dos franqueados. Cabe ao franqueado, no processo de inovação, monitorar o campo, testar novos produtos e oferecer feedback ao franqueador. A inovação no franchising é uma realidade complexa que está intimamente ligada a diferentes formas de organização empresarial. (Albuquerque \& Andrade, 1996).

A estratégia inicial das farmácias magistrais era baseada em produzir fórmulas com composição diferente dos produtos que existiam no mercado por meio da personalização, ou seja, um produto para cada cliente, mas sem investir no desenvolvimento de novos ativos. Buscava-se produzir o que a indústria farmacêutica não atendia, especialmente por meio de associações de medicamentos e dosagens feitas sob medida para cada paciente. No entanto, com a disseminação do medicamento genérico e o consequente crescimento de receitas médicas usando o nome do princípio ativo ao invés da marca registrada, algumas farmácias passaram a mirar nestas prescrições (Silva; Filho \& Mendonça, 2006).

Diante da enorme competitividade do setor, o franchising se constitui em uma oportunidade para o franqueador ter acesso ao aprendizado, por meio da rede de franquias, expandir rapidamente a sua participação de mercado e compartilhar custos e riscos. (Ribeiro \& Prieto, 2009). Do ponto de vista do risco do negócio, empresas que adotam o franchising apresentam maiores taxas de sobrevivência do que negócios independentes, uma vez que o franqueador repassa ao franqueado sua tecnologia e oferece apoio nas operações da franquia (Maricato, 2006).

$\mathrm{Na}$ maioria das vezes, as micro e pequenas empresas têm apresentado certas dificuldades que, de acordo com Balestrin e Vargas (2003), envolvem obstáculos na obtenção de melhores preços e vantagens. Essas dificuldades são encontradas na compra de matérias-primas e componentes, nos custos de participação em feiras, campanhas 
publicitárias, reciclagem e treinamento da mão-deobra, atualização tecnológica, acesso a linhas de crédito e financiamento, aluguéis e, finalmente, os custos envolvidos na exportação de produtos. No sistema de franquias, muitos desses riscos podem ser mitigados.

Para Cassaroto Filho e Pires (1998), o grande problema da pequena empresa é a falta de competência para dominar todas as etapas da cadeia de valor, além da própria capacidade de gestão de todas as suas etapas. Também é muito improvável que economicamente uma pequena empresa possa dominar todas as funções da cadeia produtiva. Tal situação acaba prejudicando o desenvolvimento estratégico da empresa e, consequentemente, sua competitividade dentro de um setor. Gimenez (2000) afirma que a literatura sobre estratégias em pequenas empresas é influenciada por uma abordagem de natureza empreendedora que reconhece a influência do comportamento individual do dirigente sobre o processo de formulação e implementação da estratégia. Essa abordagem preocupa-se em estudar a ligação entre as características pessoais do dirigente e o processo de administração estratégica utilizado nas micro e pequenas empresas.

Alguns pesquisadores têm se empenhado em descrever o processo de evolução das pequenas empresas (Fagundes \& Gimenez, 2009; Santos et al., 2007). Dessa forma, duas posturas estratégicas emergem como forma de garantir a preservação das atividades das pequenas organizações, estratégias empreendedoras e conservadoras. A primeira, caracteriza-se pela constante inovação de produtos e tecnologia, orienta-se por uma posição competitiva agressiva e por uma destemida inclinação a correr riscos. A postura conservadora caracteriza-se por uma mínima inclinação à inovação, uma cuidadosa postura competitiva e uma tímida disposição para assumir riscos. Levando-se em consideração as características do dirigente da pequena empresa, tem-se que sua posição é que irá influenciar a postura estratégica de sua organização.

\section{MÉTODO}

Este estudo é quantitativo e foi sustentado em dados primários coletados diretamente por meio de questionário estruturado. Os questionários foram enviados para todos os executivos de uma rede de franquias de farmácias de manipulação brasileira por meio do Google Drive, tanto para os franqueados como para $\mathrm{o}$ franqueador. Por franqueados entende-se como sendo os proprietários das unidades franqueadas e seus farmacêuticos. Como franqueadores, considera-se o proprietário da franqueadora e seus farmacêuticos, já que estes podem ser considerados o elo entre o franqueado e o franqueador, pois são os responsáveis pelas visitas de campo, ministram treinamentos e desenvolvem novos produtos.

\section{Unidade de análise}

A rede de franquias de farmácias de manipulação, objeto desse estudo, possui sua matriz em uma capital do Nordeste do Brasil. Atua também nas regiões Norte, Nordeste, Centro-Oeste e Sudeste. Possui 74 unidades, sendo nove lojas próprias e 65 franqueadas. A opção por usar o franchising ocorreu em 1996, em razão da procura de interessados em reproduzir o sucesso da marca em diversas cidades.

Para melhor compreensão sobre o contexto no qual a empresa estuda está inserida, é necessário entender a dinâmica do mercado farmacêutico. Segundo Silva, Filho e Mendonça (2006), o mercado farmacêutico é composto pelos segmentos: medicamentos magistrais (manipulados), OTC (medicamentos sem necessidade de receita médica), similares, genéricos e medicamentos de referência (marca ou inovadores). O medicamento magistral é preparado a partir de receitas médicas com associações e dosagens específicas para cada paciente.

Farmácias de manipulação são micro ou pequenas empresas, geralmente, administradas por farmacêuticos. Assim, o farmacêutico agrega ao seu papel essencial atividades relacionadas ao preparo e uso do medicamento, atribuições de executivos. Quanto aos farmacêuticos que fazem parte da equipe do franqueador, suas atividades envolvem visitas às unidades franqueadas, elaboração de manuais e desenvolvimento de novas fórmulas a serem comercializadas por toda a rede de franquias.

$\mathrm{O}$ modelo de franquia da organização em análise se baseia na transferência da tecnologia de produção das fórmulas do franqueador para seus franqueados e permite ainda que o franqueado use a marca do franqueador. Além disso, o franqueador presta assistência aos franqueados na implantação da unidade franqueada e nas operações diárias por meio de treinamentos, auxílio nas compras de matérias-primas, conservação e uso de fórmulas manipuladas, auxílio na escolha do ponto, publicidade, consultoria de campo e esclarecimentos acerca do preparo das fórmulas.

\section{Variáveis}


O processo de formulação estratégica, que é composto pelo pensamento estratégico, a formulação estratégica e a mudança estratégica, foi medido por meio de um questionário desenvolvido e validado por Lucian, et al. (2008), com base em De Wit e Meyer (2004). No trabalho desenvolvido por Lucian et al. (2008), é obtida uma ferramenta de mensuração para investigar como é o processo de formulação estratégica. Tal instrumento pode ser aplicado em qualquer empresa, independentemente de seu tamanho e em qualquer área de atividade.

Cada item das três dimensões do pensamento estratégico, contou com dez itens. A escala utilizada é do tipo likert de cinco pontos. As opções de resposta variam de "Discordo completamente" (1) até "Concordo plenamente" (5), com um ponto neutro, "Não concordo nem discordo" (3). As perguntas estão em primeira pessoa e as três dimensões do processo de formulação estratégica foram distribuídas aleatoriamente. O questionário contou também com perguntas sobre as características sociodemográficas dos respondentes, tais como idade, gênero, grau de instrução formal, área de formação, tempo de experiência no setor farmacêutico, tempo de cargo de direção e vínculo com a franqueadora (se franqueado ou franqueador).

\section{Amostra}

Ao todo, 61 questionários completos e validados foram retornados. Deste total, 44,26\% respondentes são homens e 55,74\%, mulheres. A idade média dos respondentes foi de 37 anos, desvio-padrão de oito anos, com preponderância na faixa entre 30 e 40 anos de idade e formação acadêmica em Farmácia. O tempo médio de trabalho no setor farmacêutico é de 12 anos.

\section{ANÁLISE DE DADOS}

Os procedimentos metodológicos e de análise de dados adotados para identificar como os executivos da rede de franquias formulam suas estratégias pode ser observados na Figura 2. Os testes estatísticos utilizados foram o Coeficiente de Alpha de Cronbach (1951), análise descritiva, o teste Exacto de Fischer, Análise Fatorial e Cluster. Para a análise dos dados, utilizou-se o programa de domínio público R 3.2.0 e o SPSS 20.

O coeficiente Alfa de Cronbach (1951) foi usado para medir a confiabilidade do questionário. O Alfa de Cronbach (1951) é a média das correlações entre os itens que fazem parte de um instrumento (Streiner, 2003). Para calcular a probabilidade de associação das variáveis em análise serem independentes e pelo fato de a amostra ser relativamente pequena, o teste Exacto de Fisher foi utilizado.

Para analisar a relação entre as variáveis, utilizou-se a análise fatorial. Para Hair Jr. et al. (2005), a análise fatorial é um método que analisa padrões ou relações existentes entre variáveis e determina se a informação pode ser resumida em um conjunto menor de fatores ou componentes. Os fatores são combinações lineares das variáveis originais, assim, os fatores representam as dimensões latentes que resumem ou explicam o conjunto original das variáveis observadas.

Para uma análise mais detalhada, os gestores também foram divididos em grupos, levando em consideração as características do perfil demográfico e a similaridade entre elas. A técnica mais comumente utilizada para esse propósito e que foi utilizada neste trabalho foi a análise de agrupamentos (Everitt, 2005). Também conhecida como análise de cluster, esta técnica tem como objetivo dividir os elementos da amostra em grupos de forma que os elementos pertencentes a um mesmo grupo sejam similares entre si com respeito às variáveis (características) que neles foram medidas, e os elementos em grupos diferentes sejam heterogêneos em relação a estas mesmas características, (Mingotti, 2005). 


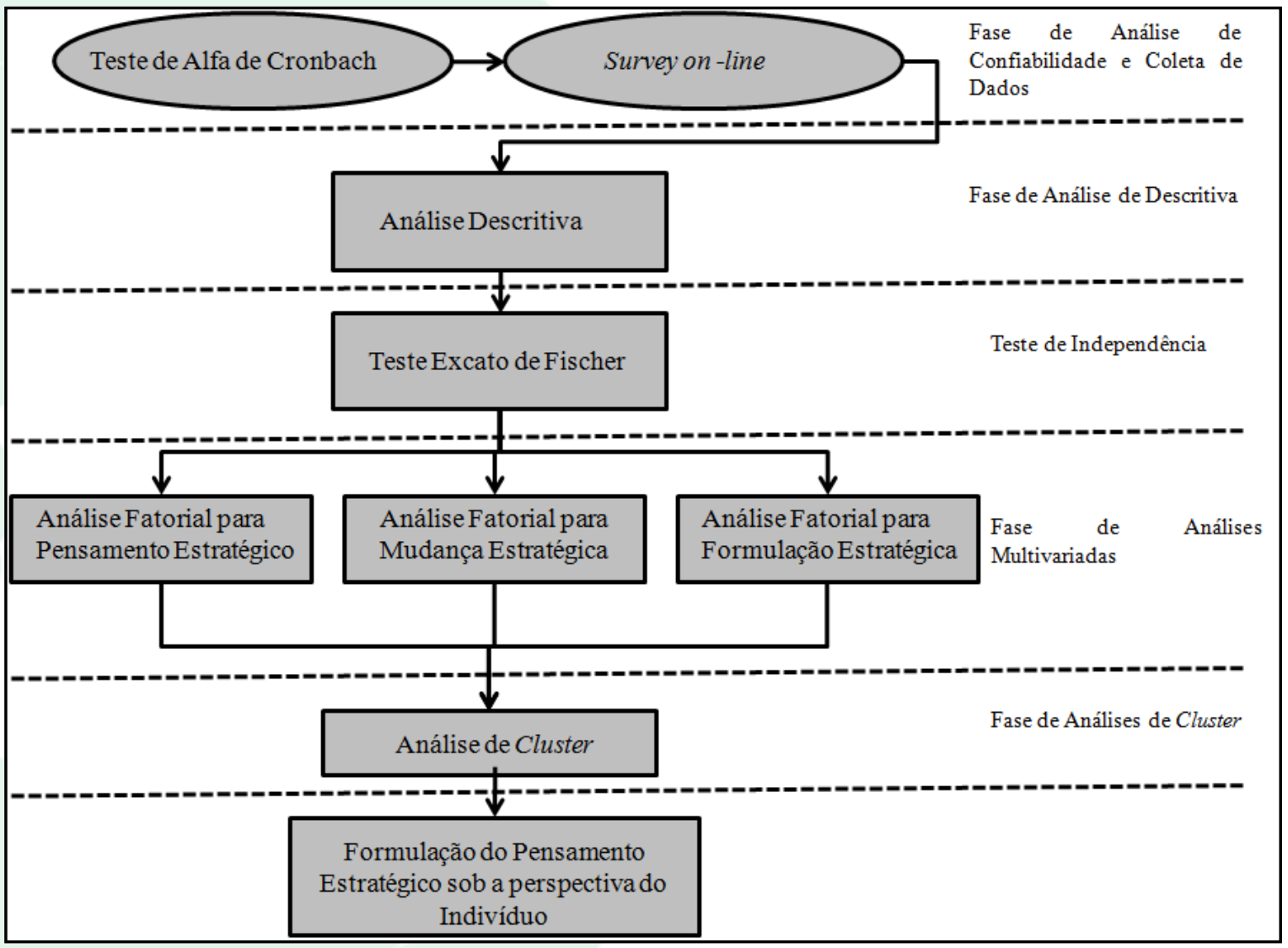

Figura 2 - Desenho metodológico

Fonte: Elaborado pelos autores (2015)

\section{RESULTADOS}

\section{Alfa de Cronbach}

Por meio do teste Alpha de Cronbach (1951) com todos os itens, percebeu-se que o conjunto de variáveis foi considerado bom com o coeficiente de 0,809 , visto que na literatura recomenda-se um coeficiente maior que 0,70 . Com o coeficiente abaixo de 0,70 , a consistência interna da escala utilizada é considerada baixa. Usualmente, são preferidos valores de alfa entre 0,80 e 0,90 (Streiner, 2003).

\section{Teste de Fisher}

Por meio do teste de Fisher, com um nível de significância de $10 \%$, verificou-se que a variável grau de instrução formal está associada com a variável "acredito que estratégias surgem de boas ideias e não de boas observações sobre os fatos" (valor $\mathrm{p}=0,021$ ) e com a variável "traço metas e/ou objetivos bem definidos para guiar as estratégias" (valor $\mathrm{p}=0,043$ ). Diante disso, há indícios que o nível de escolaridade está associado a um perfil de formulação estratégica do indivíduo que se aproxima do pensamento criativo e da formação da estratégia deliberada.

$\mathrm{O}$ teste de Fisher também apontou que a variável vínculo com a rede de franquias - cujas opções de respostas eram proprietário da franqueadora, proprietário de franquia, farmacêutico contratado pela franqueadora ou farmacêutico contratado por franquia - está associada com a variável "formulo estratégia com base na criatividade" (valor $\mathrm{p}=0,028$ ), com a variável "acredito que um plano estratégico deva ser completamente finalizado antes de se iniciar sua execução" (valor $\mathrm{p}=0,009$ ) e com a variável "creio que a mudança é algo naturalmente presente no diaa-dia de uma empresa" (valor $\mathrm{p}=0,06$ ). Portanto, rejeita-se a hipótese nula de independência. O vínculo com a rede de franquias parece estar associado a um perfil de formulação estratégica do indivíduo que se aproxima do pensamento criativo, da estratégia deliberada e da mudança estratégica evolucionária. 
A variável curso de formação está associada com a variável "acredito que as estratégias surgem no dia-a-dia à medida que as coisas vão sendo realizadas" (valor $\mathrm{p}=0,077$ ) e com a variável "acredito que planos estratégicos podem surgir à medida que se identificam novas oportunidades de ação" (valor $\mathrm{p}=0,056$ ). Essas duas associações sugerem que, em função da área de formação, a concepção da estratégia individual dos executivos pesquisados se inclina para estratégias emergentes em detrimento de estratégias deliberadas.

\section{Análise fatorial}

A matriz resultante da análise de fatores, rotacionada pelo método varimax em três interações para o pensamento estratégico pode ser observada na Tabela 1. O KMO observado foi de $0,735 \mathrm{com}$ 45 graus de liberdade e qui-quadrado de 92,788 significativo ao nível de 0,000. A Tabela 1 apresenta três fatores com suas respectivas porcentagens da variância total explicada. $\mathrm{O}$ fator 1 é o mais importante por captar a maior variabilidade com $29 \%$. O fator 2 contribui com $13 \%$ e o fator 3 com $11 \%$.

Os fatores foram nomeados de acordo com a predominância de suas variáveis nos paradoxos de cada pilar de formulação estratégica (pensamento, formação e mudança). O primeiro fator é composto por quatro variáveis do pensamento criativo e uma variável do pensamento lógico. É importante destacar que, neste fator, há uma forte presença dos elementos do pensamento criativo. Por isso, o fator foi nomeado de "Pensamento Criativo-lógico". O segundo fator é composto por três variáveis que são referentes ao pensamento lógico. Para este fator, foi dado o nome de "Pensamento Lógico". O terceiro fator é composto por duas variáveis de pensamento criativo e nomeado de "Pensamento Criativo".

Tabela 1 - Variação decorrente das variáveis Pensamento Estratégico

\begin{tabular}{|l|l|l|}
\hline Fator & Captação total (\%) & Captação Acumulada (\%) \\
\hline Fator 1 & 29,13 & 29,13 \\
\hline Fator 2 & 12,93 & 42,06 \\
\hline Fator 3 & 11,17 & 53,23 \\
\hline
\end{tabular}

Fonte: Elaborado pelos autores (2015)

É possível observar, por meio da análise fatorial, que, para os fatores 1 e 3, existe forte predominância do pensamento estratégico criativo na amostra em questão. Portanto, é possível aferir que o indivíduo tende a ter pensamentos estratégicos mais criativos em detrimento do lógico.

A matriz resultante da análise de fatores rotacionada pelo método varimax em três interações para a formulação estratégica pode ser observada na Tabela 2. O KMO observado foi de 0,518 com 45 graus de liberdade e qui-quadrado de 77,655 significativo ao nível de 0,002. A Tabela 2 apresenta três fatores com suas respectivas porcentagens da variância total explicada. $O$ fator 1 é mais importante por captar a maior variabilidade com $20,59 \%$; o fator 2 contribui com $16 \%$; o fator 3 , com $13 \%$.

Tabela 2 - Variação decorrente das variáveis para formulação estratégica

\begin{tabular}{|l|l|l|}
\hline Fator & Captação total (\%) & Captação Acumulada (\%) \\
\hline Fator 1 & 20,59 & 20,59 \\
\hline Fator 2 & 16,32 & 36,91 \\
\hline Fator 3 & 13,35 & 50,26 \\
\hline
\end{tabular}

Fonte: Elaborado pelos autores (2015) 
O primeiro fator é composto por três variáveis de formulação estratégica deliberada e por uma variável V13 de formulação emergente. Este fator foi denominado de "formulação estratégica deliberada-emergente" e expressa a predominância da formulação deliberada em detrimento da emergente. Para o segundo fator, os resultados apontaram duas variáveis para formulação emergente e uma para formulação deliberada. O segundo fator foi denominado de "formulação estratégica emergente-deliberada 1". O terceiro fator é composto, como o segundo fator, de duas variáveis de pensamento emergente e de uma variável para pensamento deliberado. Este fator foi denominado de "formulação estratégica emergentedeliberada $2 "$.

A matriz resultante da análise de fatores rotacionada pelo método varimax em três interações para a mudança estratégica, pode ser observada na Tabela 3. O KMO observado foi de 0,646 com 45 graus de liberdade e qui-quadrado de 78,049 significativo ao nível de 0,002 . A tabela 3 possui três fatores com suas respectivas porcentagens da variância total explicada, portanto, o fator 1 é mais importante por captar a maior variabilidade com 23 $\%$; o fator 2 contribui com $17 \%$; o fator 3 , com 11 $\%$.

Tabela 3 - Variação decorrente das variáveis para mudança estratégica

\begin{tabular}{|l|l|l|}
\hline Fator & Captação total (\%) & Captação Acumulada $(\%)$ \\
\hline Fator 1 & 23,32 & 23,32 \\
\hline Fator 2 & 17,08 & 40,41 \\
\hline Fator 3 & 11,29 & 51,70 \\
\hline
\end{tabular}

Fonte: Elaborado pelos autores (2015)

O primeiro fator, é composto por duas variáveis referentes a mudança estratégica evolucionária e por três fatores de mudança revolucionária. Devido a predominância, no primeiro fator, das variáveis mudança estratégica revolucionária, este fator foi denominado de "mudança estratégica revolucionáriaevolucionária". O segundo fator, é composto por uma variável referente a mudança evolucionária e uma variável referente a mudança revolucionária. Pelo fato de este fator mostrar-se equilibrado entre os dois paradoxos para a mudança estratégica, recebeu o nome de "revolucionária e evolucionária". O terceiro fator é composto por duas variáveis referentes a mudança evolucionária e a uma variável referente a mudança revolucionária. Este fator foi denominado de "mudança estratégica evolucionária-revolucionária".

\section{Cluster}

Por fim, a análise de cluster foi realizada como teste de robustez. Os gestores foram divididos em grupos, levando em consideração as características do perfil demográfico e a similaridade entre eles. A utilização da técnica de análise de agrupamento traz um grande diferencial na análise do processo de formulação estratégica pela perspectiva do indivíduo nas organizações, pois possibilita que se conheça a utilização de estratégias diferenciadas para cada subgrupo, tendo em vista as suas características específicas. Ou seja, conhecendo as práticas de estratégia com níveis mais baixos de utilização, pode-se trabalhar um desenvolvimento maior desses fatores em detrimento de outros que já encontram em um estágio mais avançado.

A análise de cluster confirmou os resultados obtidos pela fatorial nos três pilares da formulação estratégica. A fatorial mostrou equilíbrio entre o tipo de mudança evolucionária e revolucionária, o que foi ratificado pela análise de cluster. Acerca do pensamento, a fatorial apontou uma preponderância do tipo criativo, o que também se confirmou pela análise de cluster. Por fim, a fatorial e a análise de cluster, de forma geral, mostraram uma tendência para a formulação estratégica emergente.

\section{DISCUSSÃO}

Este artigo se propôs a analisar como ocorre o processo de formulação da estratégia em uma rede de franquias do setor farmacêutico, em especial farmácias magistrais. Para tanto, foi utilizado um questionário validado que observa, a partir dos pilares pensamento, mudança e 
formulação, como ocorre o processo de formulação da estratégia pela perspectiva do indivíduo.

Um fator importante que o empreendedor busca no sistema de franquias é aumentar sua probabilidade de sucesso (Espinha; Machado \& Rodrigues, 2005). Porém, para que as franquias sobrevivam, é necessário um alinhamento entre franqueado e franqueador no que diz respeito à formulação estratégica. Como o franqueador repassa ao franqueado seu know-how e fornece apoio nas operações da franquia (Maricato, 2006), inconformidades quanto a maneira de conceber e aplicar as estratégias devem ser mitigadas. Pois, após o período contratual, o franqueado pode não ter interesse em manter sua franquia, já terá adquirido todas as habilidades, conhecimento do mercado e know-how do franqueador. Nesse caso, o maior prejudicado seria o franqueador (Ribeiro \& Prieto, 2009).

Quando o empreendedor busca o sistema de franquias, sabe que não terá total autonomia na gestão de seu negócio, pois deve seguir padrões pré-definidos pelo franqueador (Gohr; Santos \& Maggioni, 2011). Para o pilar formulação estratégica, os resultados apontaram para o paradoxo predominantemente emergente. Porém, seria esperado que as estratégias deliberadas fossem preponderantes, uma vez que o franchising se baseia na utilização de sistema operacional desenvolvido e anteriormente testado (Boulay, 2010). Isso pode significar tensões entre a maneira de pensar das partes envolvidas. Mintzberg, Ahlstrand e Lampel (2010) comentaram que as organizações devem encontrar um equilíbrio entre estratégias deliberadas e emergentes, não devendo dar prioridade somente a uma delas. Por isso, é preciso que os executivos fiquem atentos a novas possibilidades e iniciativas que estratégias emergentes podem proporcionar.

Um ponto importante a ser discutido é o papel dos gestores nas redes de franquias. Na rede de franquias em estudo, a formação preponderante entre os executivos foi o curso de Farmácia. É possível que este curso não enfatize o planejamento de estratégias que abordem alguns aspectos de uma organização, tais como gestão de pessoas, finanças e marketing. Desta forma, a estratégia surge no decorrer das operações da empresa, característica de estratégias emergente.

As tensões devem ser administradas e entendidas por ambas as partes (Dias, 2004), inclusive aquelas que envolvem estratégias deliberadas e emergentes entre franqueador $\mathrm{e}$ franqueado. Isso contribui para que as decisões tomadas pela cúpula da rede de franquias sejam colocadas em prática sem grandes modificações. Assim, aumentam as chances de o franqueado administrar o negócio de acordo com as condições estipuladas pelo franqueador. Afinal, os conflitos no sistema de franquias são comuns, porém é necessário, segundo Dias (2004), trabalhar e gerenciar estes de conflitos para aproximar as partes e trazer contribuições para aperfeiçoar estas relações.

Os estrategistas da empresa estudada pensam, predominantemente, de forma criativa. Estrategistas que pensam de forma criativa tendem a não seguir um conjunto de regras predeterminadas e utilizam a intuição como ferramenta para formulação estratégica (Moore, 2006). Tendo em vista a necessidade de inovação por parte da rede de franquias, é desejável que seus executivos formulem estratégias de forma criativa, uma vez que a inovação é a chave para a rede de franquias alcançar diferenciais competitivos perante seus concorrentes.

Levando em conta que cabe ao franqueador conceber e desenvolver inovações (Albuquerque \& Andrade, 1996), é desejável que executivos de sua equipe também pensem de forma criativa. Por sua vez, como o franchising é um sistema baseado no uso de um padrão de sucesso, caso franqueados formulem estratégias predominantemente criativas sem o consentimento do seu franqueador, as chances de haver conflitos entre franqueador e seus franqueados podem aumentar.

No sistema de franquias, os estrategistas criativos podem se deparar com limitações impostas por esse sistema. Se, por um lado, o franqueado conta com economias de escala que não teria como uma pequena empresa fora do sistema de franquia (Patrício, 2007; Rocha, 2010), ele pode se sentir prejudicado pelo fato de ter pouco espaço para suas iniciativas individuais e pelas limitações de produtos e serviços a serem oferecidos (Patrício, 2007; Rocha, 2010). Portanto, a criatividade no sistema de franquias deve ser tratada como parte imprescindível para obter a vantagem competitiva.

Uma maneira para alcançar um diferencial competitivo é por meio de alianças estratégicas (Thompson \& Strickland III, 2001), o que é uma forte característica do modelo de negócio do sistema de franquia, já que o franqueado é o investidor e o franqueador, detentor da marca e do know-how. Porém, o perfil do franqueado pode ser do tipo conservador, já que ele busca, antes de mais nada, diminuir as chances de fracasso de seu negócio (Espinha; Machado \& Rodrigues, 2005). Para a amostra em questão, observou-se equilíbrio entre o tipo de mudança evolucionária e revolucionária. Como o sistema de franquia não permite uma maior flexibilidade por parte dos franqueados, tais resultados podem indicar que, para esta amostra, pode existir tensões e conflitos 
entre os executivos do franqueador e da franquia. Esses possíveis conflitos devem ser entendidos como um caminho para aperfeiçoamentos e novas contribuições na relação franqueador/franqueado.

Um outro olhar sobre a relação franqueador/franqueado pode ser observado levando em conta que uma franquia pode ser caracterizada, também, como micro ou pequena empresa. Os dirigentes de pequenas organizações, geralmente, imprimem sua marca pessoal, agindo como um filtro para a formulação de ações e decisão estratégica. Isso ocorre porque comumente a decisão nessas organizações está centralizada na figura de seu proprietário. Essa influência é importante nas primeiras etapas de vida da empresa, uma vez que a figura do dono e sua dedicação ao negócio têm uma importância crucial para a sua prosperidade. Porém, no sistema de franquia a atuação do proprietário é limitada.

As organizações, geralmente de pequeno porte, que não possuem um pessoal de staff e caracteriza-se pelo predomínio do poder centralizado no executivo principal ou proprietário, Mintzberg et al (2010) deu o nome de "organizações empreendedoras". Essas organizações possuem estrutura geralmente muito simples, bem como uma pequena hierarquia administrativa, o que faz com que as pessoas se reportem diretamente ao "chefe". Isso se deve ao fato de os empreendedores serem, na maioria das vezes, os fundadores de suas empresas e tenderem a dominar todas as etapas decisórias da organização, o que pode influenciar o processo de formação e implementação das estratégias nas micro e pequenas empresas.

\section{CONSIDERAÇÕES FINAIS}

Este estudo ressaltou a importância de a formulação da estratégia empresarial, sob a perspectiva do indivíduo em micro e pequenas empresas, no contexto do sistema franchising, especificamente no segmento de farmácias de manipulação. Esta pesquisa torna-se relevante ao tentar esclarecer o processo de formulação da estratégia em empresas que usam o sistema de franquia, tema que ainda carece de estudos mais aprofundados (Ribeiro \& Prieto, 2009). Assim, é importante destacar as implicações dos achados nessa pesquisa acerca da formulação estratégica para as redes de franquias.

Em um ambiente mutável e incerto, administrar uma rede de franquias exige do franqueador uma capacidade de considerar todas as nuances que envolvem o pensamento e a forma de fazer estratégias do franqueado. A determinação de uma estratégia adequada para uma rede de franquias, começa pela identificação de como seus participantes (franqueador e franqueado) formulam suas estratégias sob a perspectiva dos três pilares pensamento, formação e mudanças, analisando as oportunidades e os riscos no seu ambiente.

Com o estudo realizado em uma franquia do setor farmacêutico, com 74 farmácias, avaliando aspectos da rede de franquias e do processo de formulação estratégica dos gestores, observou-se que há indícios das seguintes associações: (a) o nível de escolaridade estaria associado a um perfil de formulação estratégica do indivíduo que se aproxima do pensamento criativo e da formação da estratégia deliberada; (b) o vínculo com a rede de franquias parece estar associado a um perfil de formulação estratégica do indivíduo que se aproxima do pensamento criativo, da estratégia deliberada e da mudança estratégica evolucionária e (c) a variável curso de formação está associada a estratégias emergentes.

As análises fatorial e de cluster apontaram que, de maneira geral, na rede de franquias pesquisada, os executivos formulam estratégias predominantemente criativas, emergentes e que há um equilíbrio entre mudanças evolucionárias e revolucionárias. É importante lembrar que qualquer estratégia é resultado da mente do estrategista que a elaborou. Portanto, a estratégia depende da personalidade e da capacidade cognitiva do estrategista, e, por conseguinte, suas competências gerenciais, bem como da cultura corporativa que envolve a empresa.

Como, por definição, a formulação da estratégia é realizada com o futuro em mente, os administradores-estrategistas precisam estar a par dos aspectos relativos ao ambiente de suas empresas, que são especialmente suscetíveis ao tipo de mudança que afetará o futuro de suas empresas. Neste contexto, ressalta-se a necessidade das pequenas empresas explorarem e desenvolverem sua cultura e suas competências gerenciais, de maneira consistente com suas estratégias e as demandas de mercado, ou seja, alinhar mercados, estratégias, cultura e competências.

É necessário, ressaltar as limitações deste estudo. Os resultados são apenas aplicados para a empresa estudada no tempo em questão, generalizações não são possíveis sem novos estudos. A falta de publicações sobre o processo de formulação estratégica em nível individual não permite estudos conclusivos, por isso novos estudos são necessários para que um melhor entendimento desse fenômeno seja construído.

Sugere-se, para futuras pesquisas, investigar, de forma distinta, a formulação estratégica na perspectiva de franqueador e franqueador, inclusive 
em franquias de outros setores. Além disso, recomenda-se investigar o perfil de formulação estratégica dos franqueados e comparar com o perfil procurado pelo franqueador formalizado na Circular de Oferta de Franquia. Estudos que compreendam melhor a interação entre a formulação estratégica e fatores, tais como a cultura organizacional, mecanismos e boas práticas de governança corporativa e o tipo de controle das empresas, se de controle familiar, por exemplo, também podem contribuir para o melhor entendimento do assunto.

\section{REFERÊNCIAS}

Associação Brasileira De Franchising - Abf (2015) Evolução do setor 2003-2014. Recuperado em: 19 abril 2015, de: $<$ http://www.portaldofranchising.com.br/nu meros-do-franchising/evolucao-do-setor-20032014>.

Barney, J. (2002) Gaining and sustaining competitive advantage. Upper Siddle River, NJ: Prentice-Hall.

Bogner, W. C., Thomas, H. (1993) The role of competitive groups in strategy formulation: a dynamic integration of two competing models. Journal of Management Studies, 30(1), 51-67.

Bonfilio, R. et al. (2010) Farmácia magistral: sua importância e seu perfil de qualidade. Revista Baiana de Saúde Pública, Salvador, 34(3), 653664 , jul-set.

Boulay, J.(2010) The role of contract, information system and norm in the governance of franchise systems. International Journal of Retail \& Distribution Management, 38(9), 662-676.

Cronbach, L. J. (1951) Coefficient alpha and the internal structure of test. Psychometrika.

Davidovitsch, L., Caldas, L. F., \& Silva, J.F. (2009) Estruturação das redes de fastfood: um estudo empírico sobre os antecedentes do franchising e suas implicações sobre o desempenho das firmas. Revista de Administração, 44(4), 299312.

De Wit, B., \& Meyer, R. (2004) Strategy: process, content, context. an international perspective. Minneapolis/St. Paul: West Publishing Company.
Dias, C. D. (2004) Principais conflitos do sistema franchising: caso Yázigi Internexus. Dissertação de Mestrado, Universidade Federal do Rio Grande do Sul, Porto Alegre.

Eisenhardt, K. M, Kahwajy, J. L., \& Bourgeois, L. J. (1997) Conflict and strategic choice: how top management teams disagree. California Management Review, 39(2),42-63.

Espinha, P. G., Machado, H. P. V., \& Rodrigues, R. M. I. (2005) Considerações sobre o empreendedorismo e a exploração de negócios no franchising. Artigo apresentado no Encontro de estudos sobre empreendedorismo e gestão de pequenas empresas, 2005, Curitiba, Brasil.

Everitt, B. (2005) An R and S-PLUS® companion to multivariate analysis. London: Springer.

Fagundes, F. M., Gimenez, F. A. P.(2009) Ambiente, estratégia e desempenho em micro e pequenas empresas. Revista Brasileira de Estratégia, 2(2).

Hambrick, D. C., \& Mason, P. A. (1984) Upper echelons: the organization as a reflection of its top managers. Academy of Management Review, 9(2), 193-206.

Hair Jr., J.F. et al.(2005) Análise multivariada de dados. (5. ed.) Porto Alegre: Bookman.

Kahneman, D., Tversky, A.(1979) Prospect theory Analysis of decision under risk. Econometrica, 47(2), 263-291.

Lucian, R., \& Sousa Filho, J. M. (2009) Processo de formulação estratégica pela perspectiva do indivíduo: o caso Celpe. Artigo apresentado no 3Es, Recife, Brasil.

Lucian, R., Barbosa, G. L., Sousa Filho, J. M. Pereira, F. A., \& Silva, I. M. (2008) O que há na mente de um estrategista? O uso da modelagem de equações estruturais na compreensão do processo estratégico. Brazilian Business Review, Vitória, 5(2), 89-107.

Mingotti, S. A. (2005) Análise de dados através de métodos de estatística multivariada: uma abordagem aplicada. Belo Horizonte: Editora UFMG.

Mintzberg, H., Ahlstrand, B., \& Lampel, J. (2010) Safári de estratégia: um roteiro pela selva do 
planejamento estratégico. (2. ed.) Porto Alegre: Bookman.

Merlo, E. M. (2000) O desempenho do setor de franquias no Brasil: um estudo exploratório dos principais condicionantes de performance. Tese de Doutorado, Faculdade de Economia, Administração e Contabilidade, USP, São Paulo.

Meirelles, A. de M. et al. (2000) Uma abordagem para estratégia utilizando analogias. In: Encontro Nacional da Associação de Pósgraduação em Administração, 24., Florianópolis, 2000. Anais. Florianópolis: Anpad.

Moore, M. (2006) The Ten faces of innovation: Ideos strategies for beating the devil's advocate. HR. Human Resource Planning, 29, 39.

Oliveira, D. de P. R. de. (2014) Estratégia empresarial \& vantagem competitiva: como estabelecer, implementar e avaliar. (9. ed.) São Paulo: Atlas S. A.

Patrício, P. P. (2007) Análise das restrições recorrentes do relacionamento franqueadofranqueador: a construção de uma teoria substantiva sob a ótica do franqueado. Dissertação de Mestrado, Universidade do Vale do Itajaí, Biguaçu.

Porter, M.E.(1986) Estratégia competitiva: técnicas para análise de indústrias e da concorrência. Rio de Janeiro: Elsevier.

Reger, R. K., \& Huff, A. S. (1993) Strategic groups: a cognitive perspective. Strategic Management Journal, 14(2), 103-124.

Ribeiro, B. B. e Prieto, V. C.(2009) Franquia varejista como vantagem competitiva: múltiplos estudos de caso no segmento de farmácias e drogarias. Gestão \& Regionalidade, 25(75), 105-118.

Rocha, F. B. (2010) Impacto da postura comportamental do franqueado e de sua relação com o franqueador no desempenho da franquia. Dissertação de Mestrado, Pontifícia Universidade Católica do Paraná, Curitiba.
Rocha, D.T.da et al.(2011) Processo de formação de estratégia em pequenas empresas: um estudo bibliométrico e sociométrico. Revista da Micro e Pequena Empresa, Campo Limpo Paulista, 5(1), 102-119, jan-abr.

Santos, L. S. S., Alves, R. C., Almeida, K. N. T.(2007) Formação da estratégia nas micro e pequenas empresas: um estudo no Centro-oeste Mineiro. Revista de Administração de Empresas, 47(4), out-dez.

Silva, V., \& Azevedo, P. (2007) Formas plurais no franchising de alimentos: evidências de estudos de caso na França e no Brasil. Revista de Administração Contemporânea, 11, 129-152.

Silva, R. F., Filho, A. P. N. \& Mendonça, D. C. (2006) Estratégias competitivas no mercado farmacêutico brasileiro: uma abordagem sobre $o$ setor magistral. Artigo apesentado no Simpósio de Engenharia de Produção, 13 Bauru, Brasil.

Streiner, D. L. (2003) Being inconsistent about consistency: when coefficient alpha does and doesn't matter. Journal of Personality Assessment, 80(3), 217-222.

Thompson Junior, Arthur A. \& Strickland III, Alonso J.(2001) Strategic management: concepts and cases. New York: McGraw-Hill.

Tikoo, S. (2005) Franchisor use of influence and conflict in a business format franchise system. International Journal of Retail \& Distribution Management, 33(5), 329-342.

Tushman, M. L., \& O Reilly, C. A. (1996) III Ambidextrous Organizations: Managing Evolutionary and Revolutionary Change. California Management Review, 38(4), 8-30.

Tripsas, M., \& Gavetti, G. (2000) Capabilities, cognition and inertia: evidence from digital imaging. Strategic Management Journal, 21, 1147-1161.

Wernerfelt, B. (1984) A resource-based view of the firm. Strategic Management Journal, 5(2), 171180, April/June. 

